\title{
Potencial de preparados de cavalinha (Equisetum sp.) na síntese de metabólitos de defesa em cotilédones de soja (Glycine max L.) e o efeito sobre o crescimento de Rhizoctonia solani Kuhn, in vitro.
}

\author{
GUIMARÃES, SS 1; MAZARO, SM 1; FREDDO, ÁR 1 ; WAGNER JÚNIOR, A 1 \\ 'Universidade Tecnológica Federal do Paraná (UTFPR), Campus Dois Vizinhos, Estrada para Boa Esperança, \\ Km 4, CEP: 85.660-000, Dois Vizinhos, PR. E-mail: sa_santos@hotmail.com(autor corresp.);sergio@utfpr.edu. \\ br; alvaro.freddo@hotmail.com; americo@utfpr.edu.br
}

\begin{abstract}
RESUMO: Foram desenvolvidos dois experimentos com objetivo de avaliar o potencial de preparados de cavalinha (Equisetum sp.) na síntese de metabólitos de defesa em cotilédones de soja (Glycinemax L.) e o efeito sobre o crescimento de Rhizoctonia solani, in vitro. O delineamento experimental utilizado para os experimentos foi inteiramente casualizado em esquema fatorial 3x5 (formas de extração x concentrações), com quatro repetições. As formas de extração foram extrato alcoólico, infusão e maceração, nas concentrações de zero; 1; 10, 20 e 40\%. No primeiro experimento foi avaliada a indução de compostos de defesa vegetal em cotilédones de soja em resposta aos derivados a base de cavalinha, sendo quantificada a atividade da enzima fenilalanina amônia-liase (FAL), via espectofotometria, a fitoalexina gliceolina, e o teor de fenóis totais. No segundo experimento, in vitro, a unidade experimental foi uma placa de Petri, sendo os preparados de cavalinha incorporados ao meio BDA (Batata-dextrose e Agar) e avaliado o crescimento micelial de $R$. Solani. Os preparados de extrato alcoólico, infusão e maceração de cavalinha apresentaram capacidade de indução das fitoalexinas gliceolinas em cotilédones de soja, bem como, ativaram o metabolismo de compostos fenólicos. Entre os preparados, o extrato alcoólico e a maceração, se sobressaem sobre a infusão. Os preparados de extrato alcoólico, infusão e maceração de cavalinha em todas as suas concentrações inibem o crescimento do fungo $R$. solani, in vitro.
\end{abstract}

Palavras-chave: fitalexinas, fenilalanina amonialiase, efeito fungistático.

ABSTRACT: Potential of horsetail (Equisetum sp.) derivatives on the synthesis of defense metabolites using soybean (Glycine max L.) cotyledons and their effect on the in vitro growth of Rhizoctonia solani Kuhn. Two experiments were carried out in the Federal Technological University of Paraná - Dois Vizinhos Campus - with the aim to evaluate the potential of horsetail (Equisetum sp.) derivatives for the synthesis of defense metabolites in soybean (Glycine max L.) cotyledons and their effect on the in vitro growth of Rhizoctonia solani. The experimental design was completely randomized in a $3 \times 5$ factorial design (extraction form $x$ concentration), with four replications. The extraction forms were alcoholic extract, infusion and maceration and the concentrations tested were zero, 1, 10, 20 and 40\%. In the first experiment, we evaluated the induction of plant defense in soybean cotyledons as a response to horsetail derivatives through spectrophotometry according to phytoalexin glyceollin, phenylalanine ammonia lyase enzyme activity (PAL) and total phenols. In the second experiment, in vitro, the experimental unit was a Petri dish, and the horsetail derivatives were incorporated into medium culture (potato dextrose agar), and we evaluated the mycelial growth of $R$. solani. The alcoholic extract, infusion and maceration of horsetail derivatives presented phytoalexin glyceolin induction in soybean cotyledons, in addition to activating the metabolism of phenolic compounds. Among the derivatives, the alcoholic extract and the maceration form of extraction were superior in relation to the infusion. The alcoholic extract, infusion and maceration of horsetail derivatives inhibited the in vitro growth of $R$. solani in all concentrations.

Key words: phytoalexins, phenylalanine ammonia lyase, fungistatic effect.

Recebido para publicação em 08/09/2012 


\section{INTRODUÇÃO}

As plantas estão expostas a uma ampla gama de patógenos causadores de doenças que em sua maioria são controladas mediante utilização de agroquímicos que podem desencadear efeitos maléficos ao meio ambiente e a saúde de agricultores e consumidores.

Diversos trabalhos mostram o potencial de plantas medicinais no controle de fitopatógenos, tanto por sua ação fungitóxica direta, inibindo o crescimento micelial e a germinação de esporos, quanto pela capacidade de ativar o metabolismo de defesa das plantas, como o acúmulo de fitoalexinas, indicando a presença de moléculas com características elicitoras (Cunico et al. 2004; Amaral \& Bara 2005; Brand et al. 2006; Souza et al. 2007; Celoto et al. 2008; Itako et al. 2008; Gonçalves et al. 2009; Silva et al. 2009; Camatti-Sartori et al. 2011; Venturoso et al. 2011).

Nesse sentido, as pesquisas vem avaliando diversos produtos, muitos deles já utilizados pelos agricultores, como exemplo a utilização de pimentado-reino (Piper nigrum L.), alho (Allium sativum L.), samambaia (Pleopeltis pleopeltifolia) e eucalipto (Eucalyptus sp.) (Bettiol et al. 2006; Paula Júnior et al. 2006).

A Equisetum sp. conhecida como cavalinha, rabo-de-cavalo, erva-canudo, lixa-vegetal, entre outros, pertence a família das Equisetaceae, nativa do Continente Americano e distribuída por todo território brasileiro principalmente na região sul (Lorenzi 2000; Santos et al. 2009). Apresenta em sua constituição fitoquímica: ácido sílico, ácido gálico,resinas, sais de potássio, tiaminas, luteolina, saponinas, compostos inorgânicos (Ca, Mg, Na, F, $\mathrm{Mn}, \mathrm{Si}, \mathrm{S}, \mathrm{P}, \mathrm{Cl}$ e K), triglicerídios, óleos, flavonóides (isoquercetina, equisetrina, canferol, galutenina, fitosterol), triglicerídeos (ácido oléico, esteárico, lenoléico e linolênico), alcalóides (metosapiridina, nicotina, palustrina, palustrinina), vitamina $\mathrm{Ce}$ taninos (Bertalot et al. 2010).

Seu uso medicinal se dá para o tratamento de doenças reumáticas, cálculos renais e demais infecções do trato urinário. Possuindo também ação diurética, anti-hemorrágica e anti-anêmica (Santos et al. 2009).

$\mathrm{Na}$ agricultura, estudos foram realizados utilizando extratos de cavalinha no controle de doenças, como no controle de Mycosphaerella fragariae no morangueiro (Bertalot et al. 2014), controle de Botrytis sp. (Camatti-Sartori et al. 2011) e controle de crestamento bacteriano em feijão de vagem (Paixão et al. 2003).

Estudo desenvolvido por Padilha et al. (2007), relataram o potencial da cavalinha no processo de indução de resistência em plantas com ativação das fitoalexinas.
As fitoalexinas são metabólitos secundários que apresentam atividade antimicrobiana. Esses compostos apresentam importantes ações na proteção contra uma ampla gama de patógenos, dentre eles os fungos fitopatogênicos. Em soja, a fitoalexina gliceolina mostra-se importante na interação dessa leguminosa com fitopatógenos, sendo a utilização de seus cotilédones uma ferramenta usada para estudos envolvendo ação elicitora de moléculas de origem biótica e abiótica (Schwan-Estrada et al. 2000). Os resultados obtidos em cotiledones podem abrir possibilidades para estudos em diversos patossistemas de importãncia agrícola.

Além da quantificação de fitoalexinas, a identificação da ativação de rotas de defesa vegetal é importante para o desenvolvimento de estratégias de defesa vegetal, como a quantificação de compostos fenólicos e a atividade da enzima fenilalanina amonia-liase (FAL). Os compostos fenólicos são responsáveis por uma grande diversidade de funções nos vegetais, são biossintetizados por meio de diferentes rotas, razão de sua heterogenicidade. Os compostos fenólicos mais abundantes são derivados da fenilalanina, por meio de eliminação de amônio para formar ácido transcinâmico. Essa reação é catalizada pela $F A L$, que é a enzima chave na indução de resistência, por estar diretamente envolvida no metabolismo de fenilpropanóides (Taiz \& Zeiger 2004).

Assim, o estudo da síntese de compostos de defesa vegetal, especialmente em uma especie como a "cavalinha", a qual já vem sendo utilizadas no controle de fitopatógenos de forma empírica pelos agricultores, bem como estudar seu potencial como efeito fungistático sobre um patógeno de dificil controle, abre perspectivas para descoberta de novos produtos naturais com atividade antimicrobiana e cujas estruturas podem servir como modelo para a síntese química de defensivos agrícolas naturais (Braga 2014).

O presente trabalho teve como objetivo avaliar o potencial de preparados de Cavalinha (Equisetum sp.) na síntese de metabólitos de defesa em cotilédones de soja (Glycine max L.) e o efeito sobre o crescimento de Rhizoctonia solani Kuhn, in vitro.

\section{MATERIAL E MÉTODOS}

Os trabalhos foram conduzidos no Laboratório de Fitopatologia da Universidade Tecnológica Federal do Paraná (UTFPR), Campus Dois Vizinhos (PR), nos meses de fevereiro a junho do ano de 2011. 
Foram utilizados os caules da planta fresca, logo após sua coleta, para a elaboração dos preparados. Esses foram extraídos por meio de infusão, maceração e extrato alcoólico; para ambos a solução padrão foi preparada na concentração de $40 \%$ e as demais concentrações (1, 10 e $20 \%$ ) foram diluídas a partir dessa.

A infusão foi preparada utilizando $1000 \mathrm{ml}$ de água destilada fervente, adicionando em seguida $400 \mathrm{~g}$ de Equisetum sp., permanecendo em repouso por 20 minutos em recipiente fechado, após esse repouso a solução foi filtrada e conservada sob refrigeração e ao abrigo da luz até sua utilização.

Para a maceração foram levados ao liquidificador $400 \mathrm{~g}$ da planta e $1000 \mathrm{~mL}$ de água fria destilada; após a trituração, a solução permaneceu em repouso por 8 horas sob refrigeração e ao abrigo da luz, após procedeu-se com a filtragem e conservação sob refrigeração e ao abrigo da luz até sua utilização.

Para preparo do extrato alcoólico, $400 \mathrm{~g}$ da planta foram adicionados de $1000 \mathrm{~mL}$ de álcool etílico absoluto, a solução foi deixada em repouso por 48 horas, evaporada em evaporador rotativo e resuspensa em água, após procedeu-se com a conservação sob refrigeração e ao abrigo da luz até sua utilização.

No experimento de indução de metabolitos de defesa vegetal em cotilédones de soja em resposta a extratos de Equisetum sp., as sementes de soja foram semeadas em gerbox contendo areia autoclavada e mantidas em laboratório a temperatura de $25^{\circ} \mathrm{C}$.

Após 10 dias os cotilédones das plântulas foram removidos, lavados com água destilada e pesados. Na face abaxial dos cotilédones foi feito um corte superficial e, sobre esse corte, depositado $40 \mu \mathrm{L}$ da preparação elicitora ou de água destilada quando testemunha. Os cotilédones foram arranjados em placas de Petri (quatro por placa) forradas com disco de papel de filtro umedecidos com água destilada. As placas tampadas e não vedadas, foram mantidas em câmara de crescimento (B.O.D.), a $26^{\circ} \mathrm{C}$, no escuro.

Após 20 horas, os cotiledones foram retirados das placas e colocados em tubos plásticos contendo $15 \mathrm{~mL}$ de água destilada, e então estes tubos foram agitados em mesa agitadora por uma hora para a extração de gliceolina. A solução foi filtrada em papel de filtro Whatman n॰41 e a absorbância determinada em espectofotômetro em comprimento de onda de $285 \mathrm{~nm}$, de acordo com metodologia descrita por Labanca (2002). Os cotilédones foram então congelados e utilizados para as análises de compostos fenólicos e FAL.

A quantificação dos compostos fenólicos totais foi realizada em duas etapas, seguindo o método adaptado de Bieleski \& Turner (1966). A primeira compreendeu a extração dos fenóis totais, realizada a partir da adição de $4 \mathrm{~mL}$ da solução metanol, clorofórmio e água (MCA), na relação 6: 2,5: $1,5 \mathrm{v} / \mathrm{v}$, no material vegetal, com trituração em almofariz à temperatura ambiente, seguida de uma centrifugação a $6000 \mathrm{~g}$ por $20 \mathrm{~min}$, sendo coletado o sobrenadante. Posteriormente, foi realizada nova extração do resíduo remanescente, adicionando-se $4 \mathrm{~mL}$ de MCA, centrifugando novamente a $6000 \mathrm{~g}$ por 20 min e o sobrenadante sendo adicionado ao primeiro, obtendo-se assim o extrato MCA. A esse extrato foi adicionado $1 \mathrm{~mL}$ de clorofórmio e $1,5 \mathrm{~mL}$ de água destilada, procedendo-se nova centrifugação a $6000 \mathrm{~g}$ por $15 \mathrm{~min}$ para separação das fases. A segunda etapa compreendeu a determinação de fenóis totais realizada pelo método adaptado de Jennings (1991). A quantificação de fenóis foi feita através de uma curva padrão utilizando tirosina. As amostras foram preparadas a partir da retirada de uma alíquota de $0,5 \mathrm{~mL}$ da parte superior do tubo de extração dos fenóis (extrato MCA), a seguir adicionado $0,5 \mathrm{~mL}$ de água destilada, mais 0,5 $\mathrm{mL}$ do reagente Folin-Ciocalteau. Após $15 \mathrm{~min}$, foram adicionados $5 \mathrm{~mL}$ do reagente alcalino "A" (preparado com carbonato de sódio a $2 \%$ em uma solução de hidróxido de sódio $0,1 \mathrm{~N}$ ), permanecendo durante 50 minutos até a leitura da absorbância em 760 nm, em espectrofotômetro, modelo UV-1601Shimadzu. No controle negativo, foi usada água destilada no mesmo volume do extrato vegetal. $O$ resultado foi expresso em mg.g de tecido-1.

Para quantificação da enzima fenilalanina amônia-liase ( $F A L$ ) foi pesado $1,0 \mathrm{~g}$ de cotilédones de cada um dos respectivos tratamentos. Após a pesagem, as amostras foram transferidas para almofariz previamente gelado, acrescentando-se $6,0 \mathrm{ml}$ do tampão de extração, a $4^{\circ} \mathrm{C}$, macerandose a mistura completamente, e centrifugando-a em seguida, a $6000 \mathrm{~g}$ por $10 \mathrm{~min}$ a $4^{\circ} \mathrm{C}$. O sobrenadante foi diluído antes da análise da atividade enzimática e da determinação da proteína solúvel, pipetandose $200 \mu \mathrm{l}$ do mesmo e acrescentando-se $5 \mathrm{ml}$ do tampão de extração $(22,2 \mathrm{~g}$ de Tris; $0,37 \mathrm{~g}$ de EDTA; 85,5 g de sacarose; $10 \mathrm{~g}$ de PVP). Nesta solução completou-se o volume para $1000 \mathrm{ml}$ de água destilada, após ajustar $\mathrm{o} \mathrm{pH}$ para 8,0 com ácido clorídrico 2,0 N. A atividade da FAL foi avaliada com base na diferença de absorbância resultante da conversão da fenilalanina em ácido trans-cinâmico (Hyodo et al. 1978). Para isto, foi pipetado em tubos de ensaio $1,5 \mathrm{ml}$ de cada extrato enzimático, acrescentando-se $1,0 \mathrm{ml}$ do tampão de extração e $0,5 \mathrm{ml}$ de fenilalanina $\left(49,6 \mathrm{mg} \mathrm{ml}^{-1}\right)$ ou água destilada na prova em "branco". A mistura foi incubada a $40^{\circ} \mathrm{C}$ por uma hora, interrompendo-se a reação com banho de gelo e procedendo-se as

Rev. Bras. PI. Med., Campinas, v.17, n.1, p.143-149, 2015. 
leituras espectrofotométricas a $290 \mathrm{~nm}$ (Rodrigues et al. 2006).

No experimento do efeito fungistático in vitro de preparados de Equisetum sp., no meio BDA (batata-dextrose-ágar), ainda não solidificado, foi adicionado, o extrato vegetal (obtido anteriormente) em placas de Petri® ( $8 \mathrm{~mL}$. placa-1). Após solidificação do meio, foi transferido para o centro de cada placa, um disco de $8 \mathrm{~mm}$ de diâmetro, colonizado com o micélio do Rhizoctonia solani , obtido da micoteca da UTFPR - Câmpus Pato Branco. Posteriormente, as placas foram incubadas sob alternância de fotoperíodo de 12 horas, em temperatura de $25^{\circ} \mathrm{C}$ $\pm 2^{\circ} \mathrm{C}$. As testemunhas consistiram de discos de micélio do meio BDA com ausência do extrato vegetal.

A avaliação da atividade antifúngica dos extratos foi realizada apartir de 48 horas de incubação, para isso foram realizadas medições diárias do crescimento micelial utilizando-se paquímetro. Cada observação dessa variável foi oriunda da média entre duas medidas opostas (sentido cruzado) do diâmetro da colônia até atingir a borda.

O delineamento experimental utilizado para os experimentos foi inteiramente casualizado, em esquema fatorial $3 \times 5$ resultante da combinação de três formas de extração (extrato alcoólico, infusão e maceração) e cinco concentrações (zero; $1 ; 10$, 20 e 40\%), com quatro repetições.

Os dados das variáveis analisadas nos dois experimentos foram submetidos à análise estatística, com auxílio do software ASSISTAT 7.6 BETA. Os dados foram submetidos à análise de variância a $5 \%$ de probabilidade de erro.

\section{RESULTADOS E DISCUSSÃO}

Os preparados da cavalinha apresentaram estatisticamente ação significativa na indução das fitoalexinas gliceolinas em cotilédones de soja, uma vez que ocorreu interação significativa entre as variáveis concentrações e os preparados (Tabela 1), com destaque para os preparados obtidos através de extração alcoólica, que apresentou superioridade em todas as concentrações, exceto nas de $1 \%$ e $40 \%$ que não diferiram da maceração. $O$ extrato a base de infusão obteve menor capacidade de indução de fitoalexinas comparado com os demais, possivelmente, o processo de extração com água quente desestruturou algumas moléculas, que com a maceração e o extrato alcoólico se mantiveram ativas.

Quanto as concentrações para cada forma de obtenção dos preparados, o extrato alcóolico juntamente com a maceração tiveram a maior resposta de indução das fitoalexinas gliceolinas nas concentrações de $40 \%$. Já para os preparados a base de infusão, ocorreu resposta na indução de fitoalexinas em concentrações igual ou maiores que $1 \%$, no entanto, a resposta obtida pela infusão foi inferior estatisticamente as demais formas de extração dos preparados nestas mesmas concentrações.

A resposta diferenciada quanto a defesa vegetal demonstra que existe especificidade quanto ao potencial de indução de defesas entre as espécies, considerando concentrações e formas de extração dos metabolitos indutores. Tal fato também foi observado em outros trabalhos como o desenvolvido por Gouvea et al. (2011) os quais avaliaram extratos de alho e de neem na indução de fitoalexinas de soja. Ainda Luckmann et al. (2007) ao avaliar diversas formas de extração de alecrim (Rosmarinum officinalis L.), observaram que o extrato alcoólico de folhas e o óleo essencial da planta possuem ação na indução de fitoalexinas gliceolinas em cotilédones de soja. Guimarães et al. (2007) testando diferentes preparados de Cravo-daíndia (Syzygium aromaticum L.), verificaram que os preparados da planta apresentaram capacidade de indução das fitoalexinas em cotilédones de soja, e o efeito foi mais pronunciado para extrato alcoólico e decocção nas concentrações acima de 10\% e infusão e maceração na concentração de $40 \%$.

TABELA 1. Indução de fitoalexina gliceolina (Abs. $285 \mathrm{~nm} / \mathrm{g}$.p.f.) em cotilédones de soja pelo tratamento com derivados de Equisetum sp. obtidos por extrato alcoólico, maceração e infusão. UTFPR - Câmpus Dois Vizinhos, 2011.

\begin{tabular}{cccccc}
\hline \multirow{2}{*}{ Forma de Extração } & $\mathbf{5}$ Concentração (\%) \\
\cline { 2 - 6 } & $\mathbf{0}$ & $\mathbf{1}$ & $\mathbf{1 0}$ & $\mathbf{2 0}$ & $\mathbf{4 0}$ \\
\hline Extrato alcoólico & $0,067 \mathrm{a} \mathrm{E} \mathrm{E}^{*}$ & $0,18 \mathrm{a} \mathrm{D}$ & $0,3 \mathrm{a} \mathrm{C}$ & $0,4 \mathrm{a} \mathrm{B}$ & $0,51 \mathrm{a} \mathrm{A}$ \\
Maceração & $0,067 \mathrm{a} \mathrm{D}$ & $0,17 \mathrm{ab} \mathrm{C}$ & $0,18 \mathrm{~b} \mathrm{C}$ & $0,29 \mathrm{~b} \mathrm{~B}$ & $0,45 \mathrm{a} \mathrm{A}$ \\
Infusão & $0,067 \mathrm{a} \mathrm{B}$ & $0,13 \mathrm{~b} \mathrm{~A}$ & $0,14 \mathrm{~b} \mathrm{~A}$ & $0,15 \mathrm{c} \mathrm{A}$ & $0,16 \mathrm{~b} \mathrm{~A}$ \\
\hline CV (\%) & \multicolumn{5}{c}{8,43} \\
\hline
\end{tabular}

*Letras minúsculas na coluna e maiúsculas na linha diferem entre si pelo teste de Tukey a 5\% de probabilidade.

Rev. Bras. Pl. Med., Campinas, v.17, n.1, p.143-149, 2015. 
Quanto a atividade da FAL os resultados observados demonstraram que não houve efeito significativo entre os diferentes preparados e as concentrações testadas. Possivelmente isso devese a possibilidade de que a ativação da FAL tenha ocorrido em momento diferente das avaliações, ou seja, em intervalos não observados nesse experimento, sendo que no momento das avaliações já estava em níveis similares a testemunha.

A atividade da FAL está relacionada com a resistência de plantas a patógenos, notadamente, por estar envolvida no primeiro passo da síntese dos fenilpropanóides, com participação de fenilalanina e sua conversão em ácido transcinâmico, catalizada pela FAL, resultando em compostos como fitoalexinas e, principalmente, lignina, que confere maior resistência à parede celular das plantas aos patógenos (Rodrigues et al. 2006; Mazaro et al. 2009).

Segundo Rodrigues et al. (2006), existe a possibilidade de que a síntese da FAL ocorra tardiamente, pois a ativação da enzima não depende somente dos extratos indutores, mas também podem estar relacionados a outros fatores, como ferimento ou luz. Os mesmos autores citam ainda que o pico da atividade enzimática ocorre entre 24 a 48 h após a indução, e relaciona trabalhos com indutores bióticos e abióticos em bananeira e feijoeiro evidenciado atividade tardia da FAL, aos seis, oito e 12 dias após a indução.

Os preparados de cavalinha apresentaram ação significativa na indução dos fenóis totais em cotilédones de soja, ocorrendo interação significativa entre os preparados $x$ concentrações (Tabela 2). Em relação ao extrato alcóolico e maceração as maiores respostas foram obtidas nas concentrações de $20 \%$ e $40 \%$. Já para os preparados a base de infusão, a superioridade estatistica para indução de compostos fenólicos foi alcançada nas concentrações de $1 \%$ e $40 \%$ do preparado. Observa-se que quanto a forma de obtenção dos preparados, assemelha-se estatisiticamente nas concentrações de 1 e $10 \%$. Por outro lado, o extrato alcóolico juntamente com a maceração foram superiores a infusão nas concentrações de 20 e $40 \%$.

Os compostos fenólicos, são produzidos rapidamente e se acumulam após a infecção, especialmente em variedades resistentes, são tóxicos aos patógenos. Os ácidos clorogênico, caféico e ferrúlico são exemplos de alguns desses compostos. Algumas formas de fenóis podem ser convertidas em derivados com radicais de oxigênio, extremamente reativos, tornando-se muito tóxicos (Barros et al., 2010). Segundo Bertalot et al. (2010) a Equisetum sp.é uma planta com alto teor de silício. O silício, segundo Barros et al. (2010), desencadeia um maior acúmulo de compostos fenólicos e lignina no local da injúria, e, danos a estrutura física do patógeno, pode ainda causar espessamento da parede celular devido a deposição de sílica e aumentar a capacidade fotossintética.

$\mathrm{Na}$ Figura 1 observou-se o efeito dos preparados a base de Equisetum sp. no crescimento de Rhizoctonia solani, 14 dias após a incubação, período o qual, na testemunha, o fungo atingiu as bordas das placas de Petri®.

Os resultados demonstraram efeito significativo dos preparados de cavalinha sobre a redução do crescimento do fungo Rhizoctonia solani. No extrato alcoólico a equação obtida foi linear decrescente com o aumento das concentrações do extrato de Equisetum sp. Para infusão e maceração a equação que melhor se ajustou foi a quadrática, sendo que os pontos de maior inibição do crescimento micelial para os extratos infusão e maceração foram nas concentrações de $27,95 \%$ e $29,32 \%$ respectivamente.

Tais resultados também corroboram com os observados na indução de fitoalexinas e compostos fenólicos. Quanto ao efeito das concentrações, observou-se que com o aumento das concentrações ocorreu maior efeito sobre a supressão do crescimento do fungo.

Em estudos semelhantes aos realizados, Cunico et al. (2004), avaliou o efeito antifúngico de extratos alcoólicos e aquosos de folhas, caules e raízes de Ottonia martiana sobre três fitopatógenos (Fusarium sp., Colletotrichum sp. e Rhizoctonia

TABELA 2. Teor de fenóis totais (mg.g tecido-1 ) em cotilédones de soja pelo tratamento com derivados de Equisetum sp. obtidos por extrato alcoólico, maceração e infusão. UTFPR - Campus Dois Vizinhos, 2011.

\begin{tabular}{cccccc}
\hline \multirow{2}{*}{ Forma de Extração } & \multicolumn{5}{c}{ Concentrações (\%) } \\
\cline { 2 - 6 } & $\mathbf{0}$ & $\mathbf{1}$ & $\mathbf{1 0}$ & $\mathbf{2 0}$ & $\mathbf{4 0}$ \\
\hline Extrato alcoólico & $1,14 \mathrm{a} \mathrm{C}^{*}$ & 1,63 a B & 1,82 a B & 1,95 a AB & 2,29 a A \\
Maceração & 1,14 a D & 1,77 a BC & 1,71 a C & 2,15 a AB & 2,52 a A \\
Infusão & $1,14 \mathrm{a} \mathrm{B}$ & 1,62 a A & 1,57 a A & 1,49 b AB & 1,23 b AB \\
\hline CV (\%) & \multicolumn{5}{c}{11,96} \\
\hline
\end{tabular}

*Letras minúsculas na coluna e maiúsculas na linha diferem entre si pelo teste de Tukey a $5 \%$ de probabilidade. 


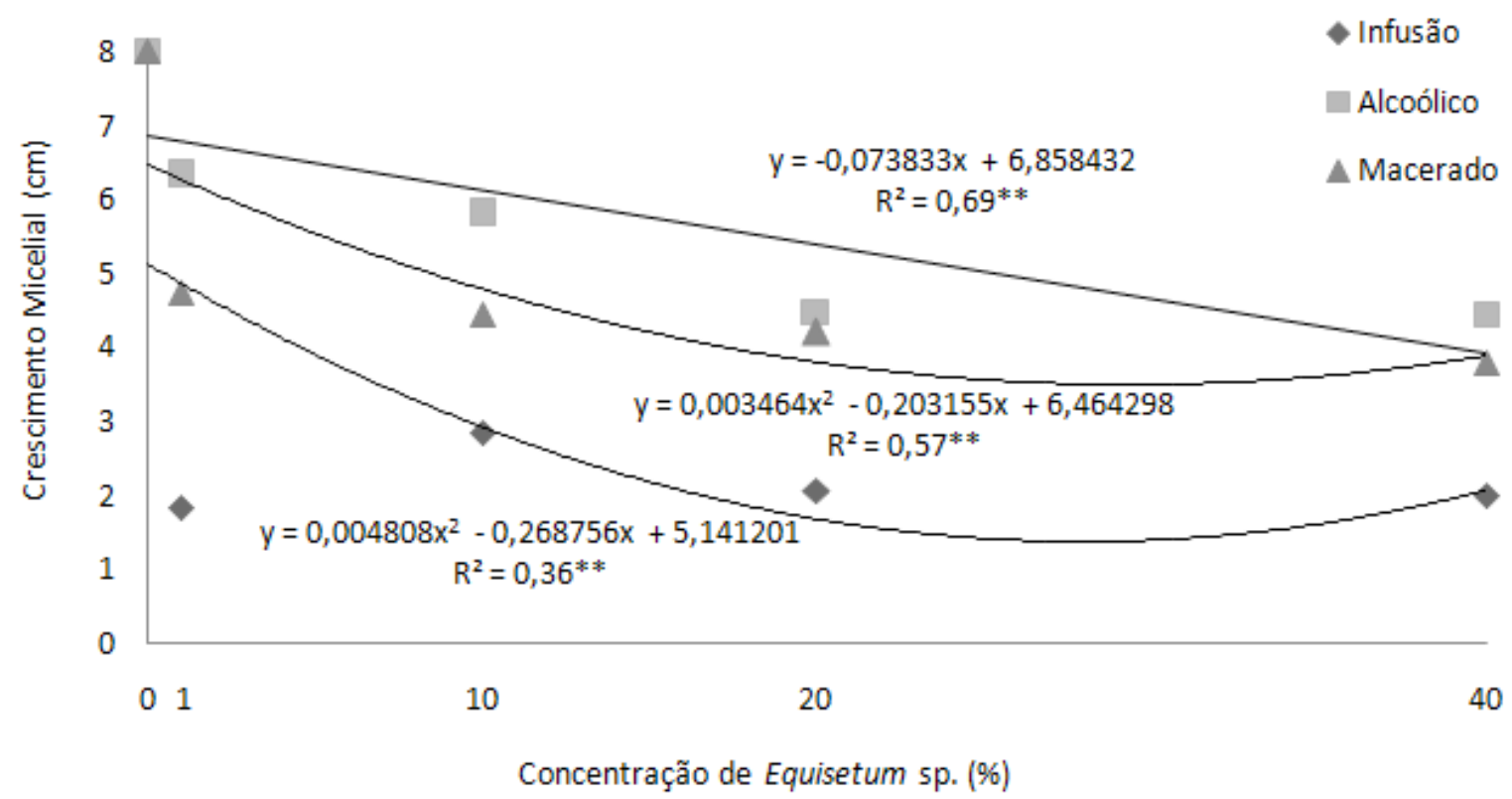

FIGURA 1. Efeito fungistático in vitro sobre $R$. solani, com a aplicação de cinco concentrações de extratos infuso, alcoólico e macerado de Equisetum sp., 14 dias após a incubação, UTFPR, Campus Dois Vizinhos, PR, 2011.

sp.), observaram que o extrato aquoso de folhas frescas apresentou maior inibição sobre Rhizoctonia $\mathrm{sp}$, enquanto que o extrato etanólico inibiu o crescimento dos três fungos em mais de $50 \%$.

Amaral \& Bara (2005), avaliando a atividade antifúngica de extratos de açafrão, coração de negro e óleo essencial de cravo-da-índia, sobre os fitopatógenos: Fusarium, Macrophomina, Rhizoctonia e Sclerotium, observaram que o extrato bruto de açafrão inibiu em mais de $50 \%$ o crescimento de $R$. solani. Mieth et al. (2007), avaliando a influencia de extratos vegetais na qualidade sanitária e fisiológica em sementes de Luehea divaricata, observou que o uso de extratos de fumo (Nicotiana tabacum) favoreceu a incidência de Rhizoctonia sp., enquanto que os extratos de pitanga (Eugenia uniflora)e cinamomo (Melia azedarach L.) inibiram seu surgimento.

Uma avaliação conjunta dos resultados obtidos nesse trabalho, pode se afirmar que compostos a base de cavalinha apresentam potencial de indução de resitência em plantas e ação fungistática sobre fitopatogenos. A forma de extração pode ser infusão, decocção e maceração, com a possibilidade de isolamento industrial das substâncias elicitoras permitindo o desenvolvimento de produtos naturais, não agressivos ao homem e ao ambiente.

Trabalhos futuros devem ser desenvolvidos, buscando avaliar a potencialidade desses compostos a base de cavalinha, em diferentes patossistemas, além de estudos mais aprimorados quanto a indução de resistência com quantificação de proteínas relacionadas a patogenicidade como quitinases e $1,3-\beta$ glucanases.

\section{CONCLUSÕES}

Pode-se inferir que os preparados de extrato alcoólico, infusão e maceração de cavalinha possuem potencial de ativação de resposta de defesa vegetal, sendo demonstrado em cotiledones de soja, além de efeito fungistático a Rhizoctonia solani, in vitro., o que demonstra potencial para novos estudos em patossistemas de interesse agrícola em sistemas agroecológicos.

\section{REFERÊNCIAS}

AMARAL, M.F.Z.J.; BARA, M.T.F. Avaliação da atividade antifúngica de extratos de plantas sobre o crescimento de fitopatógenos, Revista Eletrônica de Farmácia, Suplemento, v. 2, n. 2, p. 5-8, 2005.

BARROS, F.C. et al. Indução de resistência em plantas contra fitopatógenos, Bioscience Journal, v. 26, n. 2, p. 231-239, 2010.

BERTALOT M.J.A. et al. Controle alternativo de doenças do morangueiro. Disponivel em: <http:// www.biodinamica.org.br/Boletim_eletronico/julho_2010/ controle_alternativo_doencas_morango.pdf $>$. Acesso em 31/05/2014.

BERTALOT, M.J.A. et al. Métodos alternativos para controle de doenças fúngicas na cultura de jambu (Spilanthes oleraceae L.) através de Equisetum spp. e preparado biodinâmico 501, Rev. Bras. de Agroecologia. v. 5, n. 2,p. 264-274, 2010.

BETTIOL, W.;GHINI, R.; MORANDI, M.A.B. Alguns 
métodos alternativos para o controle de doenças de plantas disponíveis no Brasil. In: VENZON, M.; PAULA JÚNIOR, T.J.; PALLINI, A. (Ed.). Controle alternativo de pragas e doenças. 1 ed. Viçosa: EPAMIG, 2006, p. 163-183.

BIELESKI, R.L; TURNER, N.A. Separation and estimation of amino acids in crude plant extratcts by thin-layer electrophoresis and chomatograghy.Analitycal Biochemistry, Orlando, v.17, p.278-293, 1966.

BRAGA, M. R. Fitoalexinas e a defesa das plantas. Disponivel em: <www.sbq.org.br/PN-NET/texto5/defesa. htm>. acesso em 30/05/2014.

BRAND, S.C. et al. Extratos vegetais no controle de patógenos em sementes de cebola, 2006. Disponível em: <http://www.ufpel.edu.br/cic/2006/arquivos/ conteudo_CAhtml\# 00542>. Acesso em: dez/2011.

CAMATTI-SARTORI, V. et al. Avaliação in vitro de extratos vegetais para o controle de fungos patogênicos de flores, Rev. Bras. de Agroecologia. V. 6, n. 2,p. 117122, 2011.

CELOTO, M.I.B. et al. Atividade antifúngica de extratos de plantas a Colletotrichum gloeosporioides, Acta Scientia Agronômica. Maringá, v. 30, n. 1, p. 1-5, 2008.

CUNICO, M.M. et al. Avaliação antifúngica de extratos obtidos de Ottonia martiana miq. (piperaceae) sobre três fitopatógenos, Arq. Inst. Biol., São Paulo, v.71, (supl.), p.1-749, 2004.

GONÇALVES, G.G., MATTOS, L.P.V., MORAIS, L.A.S. Óleos essenciais e extratos vegetais no controle de fitopatógenos de grãos de soja. Horticultura Brasileirav. 27, n. 2, p. S102-S107, 2009.

GOUVEA, A. et al. Efeito de extratos vegetais em soja sob condições de laboratório e campo. Revista Brasileira de Agroecologia. V. 6, n. 2,p. 70-78, 2011.

GUIMARÃES, S.S. et al. Indução de Fitoalexinas em cotilédones de Soja (Glycine max) em resposta a derivados de capítulos florais de Cravo-da-índia (Syzygium aromaticum L.), Anais do I Seminário de Sistemas de Produção Agropecuária da UTFPR, Dois Vizinhos - PR, 2007, p. 18-21.

HYODO, $\mathrm{H}$ et al. Induction of phenylalanine ammonialyase and increase in phenolics in lettuce leaves in relation to the development of russet spoting caused by ethylene. Plant Physiology, Rockville, v. 62, p. 31-35, 1978.

ITAKO, A.T. et al. Atividade antifúngica e proteção do tomateiro por extratos de plantas medicinais. Tropical Plant Pathology, v. 33, n. 3, p. 241-244, 2008.

JENNINGS, A.C. The determination al dihydroxy phenolic compounds in extracts of plant tissues. Analitycal Biochemistry, Orlando, v.118, p.396398, 1981.

LABANCA, E.R.G. Purificação parcial de elicitores presentes em Saccharomyces cerevisiae: atividade como indutores de resistência em pepino (Cucumis sativus) contra Colletotrichum lagenarium e da síntese de gliceolinas em soja (Glycine max). Piracicaba, 2002. 107p. Dissertação de mestrado. Escola Superior de Agricultura. "Luiz de Queiroz",
Universidade de São Paulo.

LORENZI, H. Plantas daninhas do Brasil: terrestres, aquáticas, parasitas e tóxicas. 3.ed., Nova Odessa: Plantarum, 2000, 640p.

LUCKMANN, D. et al. Indução de fitoalexinas em cotilédones de soja (Glycine max) em resposta a derivados de folhas de alecrim (Rosmarinus officinalis L.). Anais do I Seminário Sistemas de Produção Agropecuária, UTFPR Dois Vizinhos/PR, 2007.

MAZARO, S.M. et al. Controle do tombamento de plântulas de beterraba e tomate pelo tratamento de sementes com quitosana .Pesquisa Agropecuária Brasileira, Brasília, v.44, n.11, p.1424-1430, 2009.

MIETH, A.T. et al. Influência de extrato vegetal na qualidade sanitária e fisiológica em sementes de Luehea divaricata (Açoita-cavalo). Revista Brasileira de Agroecologia. v.2,n.2, p. 1240-1242, 2007.

PADILHA, T.R. et al. Indução de fitoalexinas em cotilédones de soja (Glycine max) em resposta a derivados de cavalinha (Equisetum giganteum). Anais do I Seminário de Sistemas de Produção Agropecuária da UTFPR, Dois Vizinhos - PR, 2007, p. 30-33.

PAIXÃO, G.L.S. et al. Atividade de tinturas de plantas medicinais sobre o crestamento bacteriano comum em feijão vagem. Revista Brasileira de Horticultura, Brasília, v. 21, n. 2, jul. 2003.

PAULA JÚNIOR, T.J. et al. Controle Alternativo de doenças de plantas - Histórico.In: VENZON, M.; PAULA JÚNIOR, T. J.; PALLINI, A. (Ed.). Controle alternativo de pragas e doenças. 1 ed. Viçosa: EPAMIG, 2006, 358p.

RODRIGUES, A.A.C. et al. Indução de Resistência a Fusarium oxysporum f. sp. tracheiphilum em Caupi: Eficiência de Indutores Abióticos e Atividade Enzimática Elicitada. Fitopatologia Brasileira,v. 31, n. 5, p. 492-499, 2006.

SANTOS, M.C.; BRUSCATTO, M.H.; HECK, R.M. Reflexões fitoterápicas sobre a cavalinha (Equisetum sp.) com base na antroposofia. XVII Congresso de Iniciação de Cientifica, UFPEL, 2009.

SCHWAN-ESTRADA, K.R.F.; STANGARLIN, J.R.; CRUZ, M.E.S. Uso de extratos vegetais no controle de fungos fitopatogênicos. Revista Floresta, v.30, n. 1-2, p. 129-137, 2000.

SILVA, J.A et al. Efeito de extratos vegetais no controle de Fusarium oxysporum $f$. sp tracheiphilum em sementes de caupi. Ciência Agrotécnica, Lavras, v.33, n.2, p. P. 611-616, 2009.

SOUZA, A.E.F.; ARAÚJO, E.; NASCIMENTO, L.C. Atividade antifúngica de extratos de alho e capimsanto sobre o desenvolvimento de Fusarium proliferatum isolado de grãos de milho. Fitopatologia Brasileira, Brasília, v.32, n.6, p. 465-471, 2007.

VENTUROSO, L.R. et al. Atividade antifúngica de extratos vegetais sobre o desenvolvimento de fitopatógenos. Summa Phytopathologica, v.37, n.1, p. 18-23, 2011.

TAIZ, L.; ZEIGER, E. Fisiologia vegetal. 3ed. Porto Alegre: Artmed, 2004, 719p. 